\title{
The Utilization of Hypermedia-Based Information Systems for Developing Recyclable Products and for Disassembly Planning
}

\author{
D. Spath - Submitted by H. Weule (1) \\ Received on January 12, 1994
}

\section{Summary}

When products are considered in the context of their overall life-cycle, there is an increased requirement for information on the various life-phases involved. Information on disposal options determines the product design concept, and conversely the product design parameters affect the degree of rationalization achievable in disassembly. The resultant need to provide ecologically relevant product data both for development engineers and for disassembly planners in the context of the specific requirements concerned entails the necessity of using computer-aided information systems.

This paper presents an information concept of this kind for supporting development engineers in implementing recyclable product designs, plus a procedure for planning and supporting manual disassembly. In methodological terms, systematized approaches are employed for design evaluation and procedures for qualification-oriented disassembly planning. Initial software developments are indicated for practical applications based on Hypermedia.

\section{Keywords}

Product design, Disassembling, Information systems

\section{Foreword}

\subsection{Introduction}

Increasing requirements for incorporating environmental considerations in a product's overall life-cycle necessitate the use of computer-aided systems for product design and disassembly planning. This in turn means that design and planning engineers have to be sensitized to the environmental effects of their decisions. For ecologically compatible product life-cycle engineering, however, the additional provision of expert knowledge and planning methods in the form of computer-aided information systems are essential.

\subsection{Motivation}

The requirements which manufacturers of technical consumer products have to meet have changed significantly during the last few years. Serious environmental pollution, the limited availability of natural resources, plus the continually growing volume of refuse [Gr91] demand new concepts for product development and disposal [St91], [We93].

Increasingly stringent legislation (German Recycling Act, German Packaging Ordinance, German Electronic Scrap Ordinance, etc.) and rising disposal costs mean that environmental considerations now constitute an additional competitive factor of growing importance [AI93].

Initial approaches for incorporating these requirements into the development and planning process were reflected in VDI. Guideline 2243 "Designing Recyclable Technical Products" [VDI93]. This guideline's main objective is to standardize the various terms and definitions used in the context of recycling. Taking the guideline as a basis, some large firms have already drawn up company-specific guideline catalogues in the form of binding standards for design and planning engineers. Current focuses of research work include further development of methods for disassembly planning, process support and computer aided design for recyclability.

\subsection{Objective}

The objective of this paper is to indicate a holistic approach for the computer-aided design of environmentally compatible products and their disassembly during the planning and support stages. The basic theory and methodological approaches are briefly outlined, and initial computer-aided subsystems based on hypermedia are presented.

\section{System concept}

The starting point for the developments presented in this paper is a life-cycle-oriented approach. An altered situational context (legislative framework, market, technology, etc.) entails new task definitions [Zü91]. Information on disposal options and disassembly strategies determine the design concept, and conversely the decisions taken in the product design process determine the disposal concept.

This necessitates a bidirectional interchange of information between the design and disassembly phase. A challenge which in future can be mastered only by powerful software tools. Figure 1 shows a computerization approach to a system as described below for integrating disassembly and product development. The establishment of a common database is of pivotal importance in this context.
Design

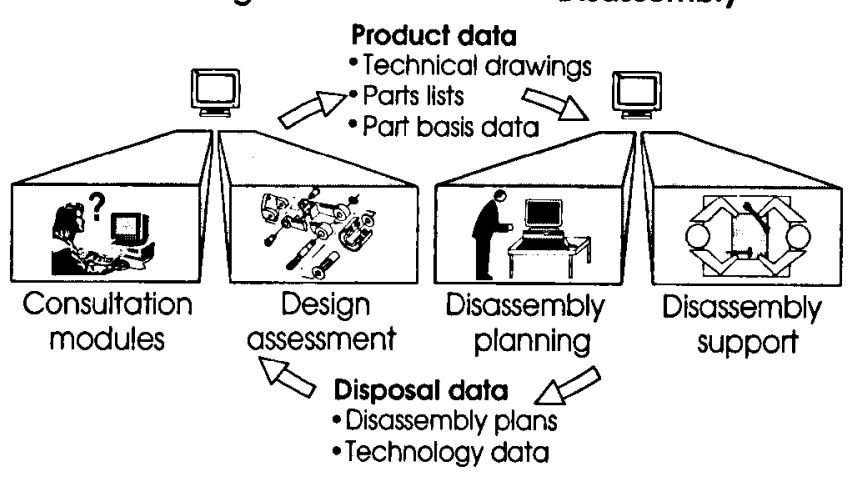

Fig. 1: System overview

\section{Computer-aided design for recyclability}

\subsection{Software architecture - design subsystem}

Methods facilitating manufacturing-friendly and assemblyfriendly product design are nowadays employed by most of the manufacturers. In view of the future necessity to cover a product's entire life-cycle in the development phase, guidelines are required for recyclable and thus disassembly-friendly design [Jo93]. So far, however, there are only generalcoverage design guidelines in existence, most of them based on VDI-Guideline 2243.

The objective is, beginning with a product-specific expansion of design guidelines, to create a software system for supporting the design engineer in developing recycling-friendly products.

Working in conjunction with industrial companies, the Institute for Machine Tools and Production Science at Karlsruhe University has analysed a variety of electrotechnical products. The product design methods developed during product optimization constitute the basis for the design subsystem (Fig. 2).

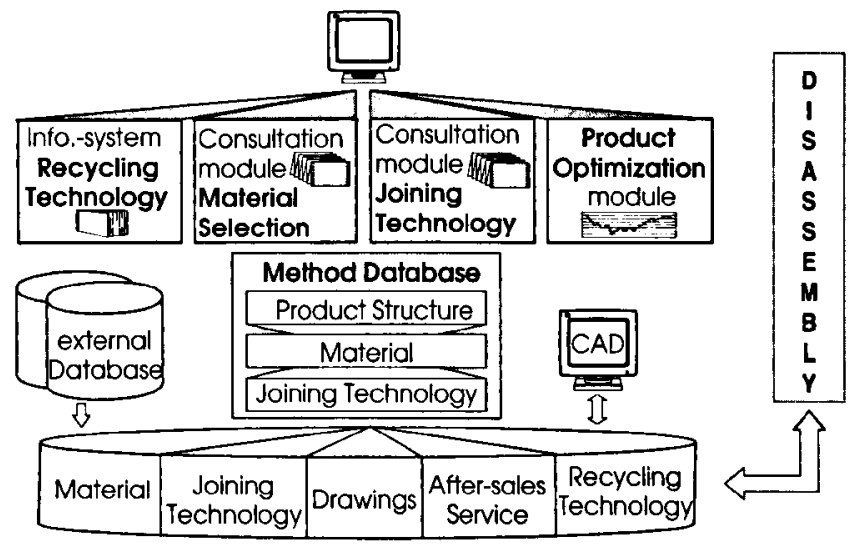

Fig. 2: Function architecture - design subsystem 


\subsection{Hypertext system - recycling technology}

The "Recycling technology" information system implemented in the form of a hypertext system provides both training enhancement and support for planning the disposal strategies and recycling concepts (Fig. 3).

The planned expansion of this system to include knowledgebased consultation modules is intended to provide a capability for simultaneous support in selecting materials and joining technology, and in implementing disassembly-friendly product structure. In a further step, systematized facilities for design assessment will be available.

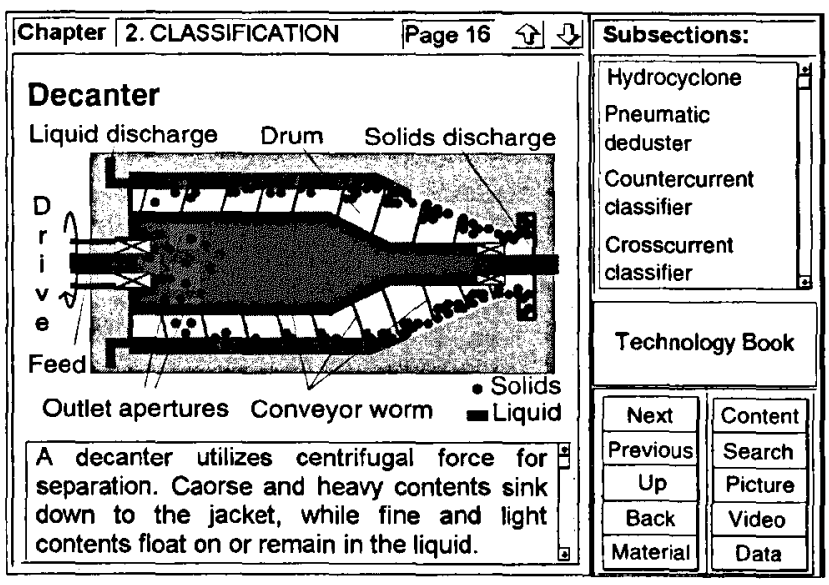

Fig. 3: "Recycling technology" information system

\subsection{Methodology for product design assessment}

"Recyclability" assessment of a product design has already been touched on by certain authors [Gü91], [Gr91], [Re87]. These methods, though permitting a comparison between different product concepts and their effects on the environment, provide little or no feedback for the design process, and thus no optimization potential either.

The approach presented here enables to assess separately the

\section{- product structure and}

- joining technology plus the materials selected.

\subsubsection{Method for product structure assessment}

The network and graph theory methods whose fundamentals are discussed in [Br93] and [Bu68] have subsequently been improved to incorporate product structure assessment methods relating to disassembly criteria.

Structural analysis is used to determine the degree of networking or complexity of the product structure concerned. The type and the number of joining elements are of secondary importance here. Graph and network techniques can be used to depict the causal interlinkages involved (cf. [Cz78]). The graph represents a geometrical structure of nodes, linked to each other over edges. In the joining structure diagram (Fig. 4 ), the nodes represent the component parts of the product concerned, and the edges the connections. In addition, the connections have been classified in terms of their functional features (e.g. number of non-detachable joining elements).

To enable different comparisons between product designs in terms of their suitability for disassembly, a mean degree of complexity (VGm) is determined from the joining degree (VG) of the adjacency matrix, in dependence on the number of parts involved (n). Thus allows the complexity and joining structure coefficients to be calculated.

Disassembly analysis is used to examine ranking orders or hierarchies of the components concerned, and the sequence of disassembly processes (cf. [Ge86]). The interdependences of modules and component parts shown in the disassembly graph are entailed by dismantling the product in accordance with a predefined disposal-strategy (e.g. pollutant removal).

The disassembly path length DP and the structural factor SF (ievels factor) result in the disassembly coefficient (Fig. 5). This enables the disassembly structure to be assessed, and the disposal strategy on which it is based as well.
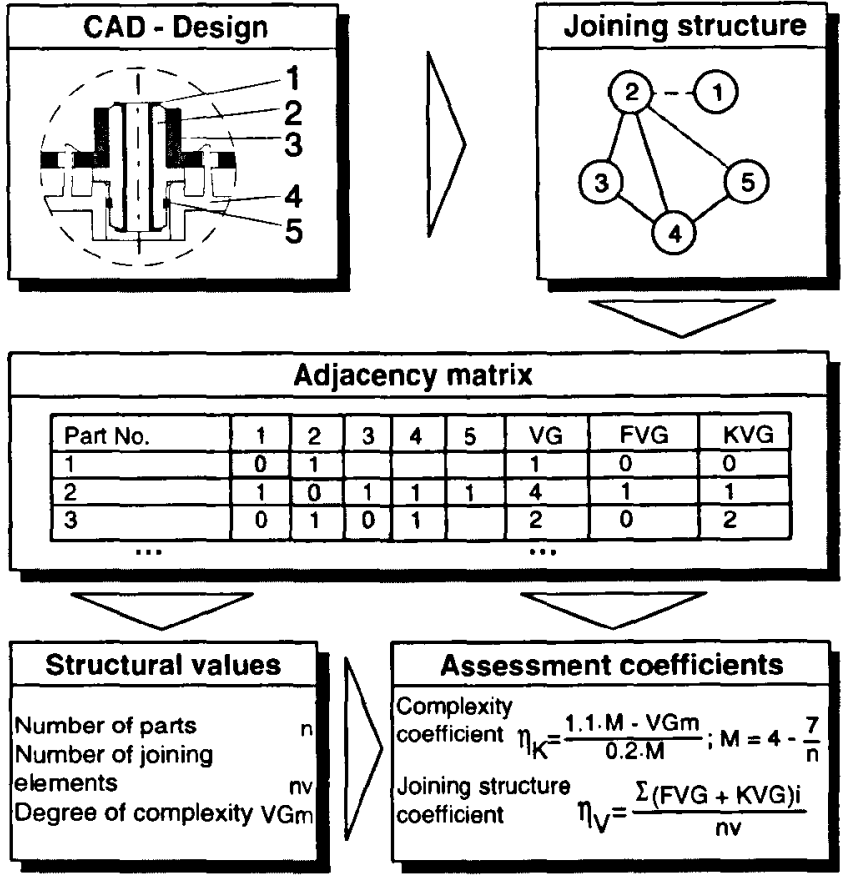

Fig. 4: Structural analysis

The coefficients for the disassembly suitability figure (DSF) are weighted $(\mathrm{Gi})$ using the following formula:

$\mathrm{DSF}=\frac{\sum \mathrm{Gi}_{\mathrm{i}} \cdot \eta_{\mathrm{i}}}{\sum \mathrm{Gi}_{\mathrm{i}} \cdot \eta_{\mathrm{i}} \text {, ideal }}=\frac{\mathrm{GD} \cdot \eta_{\mathrm{D}}+\mathrm{Gv} \cdot \eta_{\mathrm{v}}+\mathrm{GK}_{\mathrm{K}} \cdot \eta_{\mathrm{K}}}{\sum \mathrm{Gi} \cdot \eta_{\mathrm{i}, \text { ideal }}}$

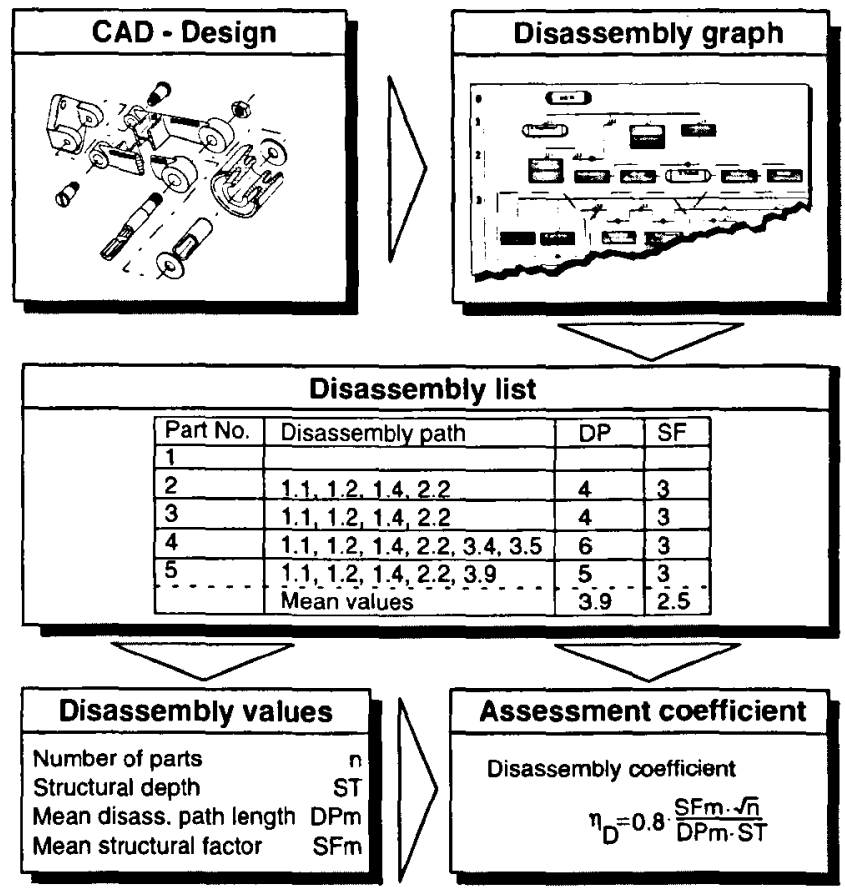

Fig. 5: Disassembly analysis

Fig. 6 compares the product structure assessment results for two technical consumer products. The recycling-friendly new product also exhibits a significantly higher disassembly suitability when assessed by this method.

Thus method of product structure assessment allows the designer to improve the product concept during early stages of design.

The comparison of the disassembly-values - for example shows a potential of improvement in the reduction of the structural depth $S T$ (reduction from $S T=4$ down to $S T=3$ ). 


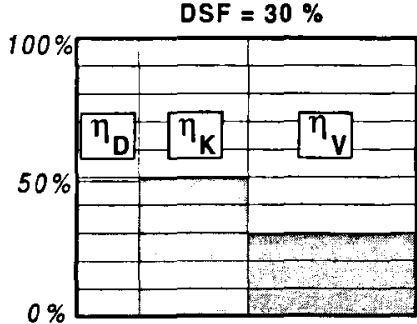

Storage water heater-old
DSF $=79 \%$

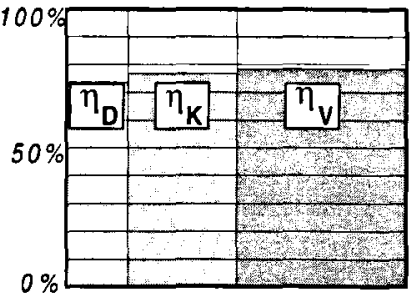

Storage water heater - new
Fig. 6: Structural assessment of technical consumer products

\subsubsection{Method for assessing material and joining technology}

When assessing the materials (metals, plastics) selected by the design engineer, the main consideration is material recycling and thus the suitability of the materials concerned for re-use. The prioritized goal here should be up-cycling, i.e. reusing the substance concerned on the same or even a higher level of value.

The materials assessment approach presented below is based on the expandable checklist concept.

The individual checklists involved assess the materials used in a product or module in terms of

- the multiplicity of materials,

- the assignability of the material to a used-material group, and thus its compatibility to a basic material of the recycling module,

- the disposal path,

- the use of problematical substances or additives rendering recycling more difficult, and

- the amount of recyclates used.

For each of the individual assessment criteria, assessment points are awarded, and calculated to form a material classification number (MKZ). A mass factor and a correction factor are assigned as a weighting.

A disassembly simulation process is used for assessing the joining technology. Determining the time required for functions like recognizing a part, recognizing a joining element, changing tools, disconnecting the part, etc. enables the effort for each of the disassembly operations to be estimated, so as to assess the disassembly suitability of the joining technology employed.

\section{Computer-aided disassembly planning and process support}

\subsection{Information required for disassembly}

The currently restricted availability of suitable technologies for material separation necessitates homogeneous materials as a precondition for high-value recycling. Antecedent disassembly is therefore the starting point for all recycling processes, enabling materials and components to be re-used [VDI93].

Technical products and modules which are used predominantly for private purposes and which can be collected for series disassembly at the end of their lifetime only in exceptional cases, are so far mainly disassembled with manual and low mechanized processes due to the relatively low numbers and wide variety of models involved.

Disassembly planning and implementation for present-day products is rendered more difficult by the following factors [Se93]:

- Product design is not adapted to subsequent disassembly and recycling (numerous disassembly steps, no easyrelease connections, diversity of materials)

- Product changes in the utilization phase (affected by repairs, soiling, corrosion)

- Product design was a long time ago, i.e. product information unavailable or incomplete

\section{- Available product data are not systematically used}

All this entails a high flexibility requirement for the disassembly process, or at least a requirement for highly qualified workers, making an industrial use not economically feasible [Jo93].
For cost-efficient and ecological disassembly of technical consumer products, flexible systems are accordingly needed using all available data from antecedent phases of a product's life-cycle (i.e. data from the design, production and utilization phases), and preprocessing these data to support disassembly costing, disassembly planning and disassembly processing. In particular, these systems must also enable lower-qualified workpersons to be flexibly employed.

\subsection{Software architecture - disassembly subsystem}

An approach to a holistic support for the disassembly of industrial series products is presented below. On the basis of a subordinated database containing product-, process- and company-specific information, tools for quotation creation, and for planning, organizing and carrying out of the disassembly process are provided.

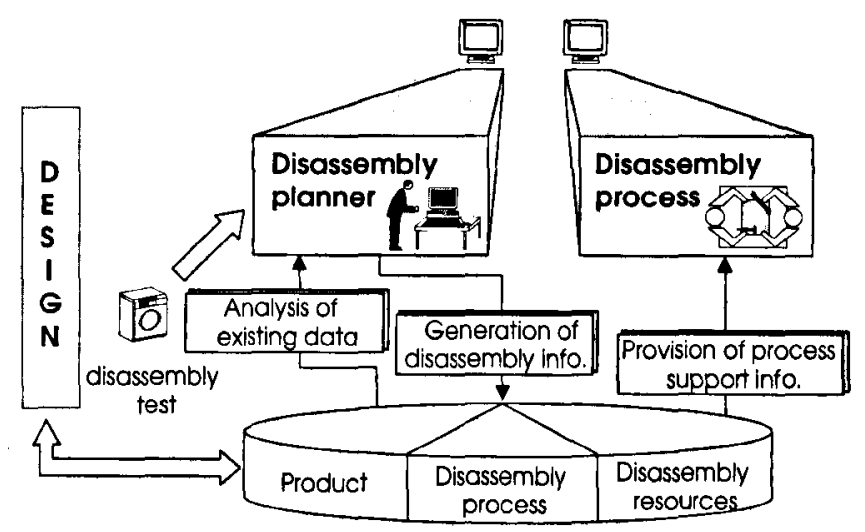

\section{Fig. 7: System functionality - disassembly subsystem}

Fig. 7 shows the functionality of the disassembly subsystem, which in the first stage of expansion contains a module for disassembly planning and another one for disassembly support. When a particular old product is encountered for the first time, it is first identified and then compared with the manufacturer's data available in the database. If only incomplete data (or none at all) are available, a test disassembly procedure has to be carried out, to generate the missing product information required for subsequent work planning. In the disassembly planning phase, first of all orderindependent type-specific disassembly information is generated, from which in the second phase (when the products are actually available), a specific disassembly procedural sequence is generated, taking into account the ongoing market and customer situation (disposal costs, revenues for secondary raw materials, etc.).

To support the flexible employment of lower-qualified workers, multimedia and hypertext technologies are used (for incorporation of graphics, exploded views, pictures, video sequences, shape and colour symbol coding) to generate structured working information for display to the disassembly workers on a qualification-matched level.

\subsection{Submodule functionality}

On the basis of already existing methods in the field of computer-aided assembly-planning, especially automated product analysis and generation of a Precedence-Graph [We89], a disassembly planning module is designed. This provides the work planner with computer-aided support for analyzing products and product information, creating disassembly work schedules and converting these into workplace information, which especially includes:

- Options for standardized processing of product-specific technological data (manufacturer's particulars)

- Processing pictorial material (exploded views, design drawings, video sequences)

- Generating a modular disassembly work schedule structured by disassembly levels

- Assignment of time and effort information to determine an optimal disassembly depth

- Assignment of animations, shape and colour symbols to individual disassembly steps

- Formation of "Variant Disassembly Schedules" for products with a similar structure 
On the basis of the general disassembly work schedule and the actual market situation (costs and revenues for further treating and recycling processes stored in the database) an economic disassembly order (disassembly depth, degree of fractionation) is determined. The generated order-dependent disassembly procedural sequence is made available for organization and carrying out of the process in the disassembly support module. It is particularly important in this context that the information density and degree of detail be matched to the needs of the individual workers involved (Fig. 8).

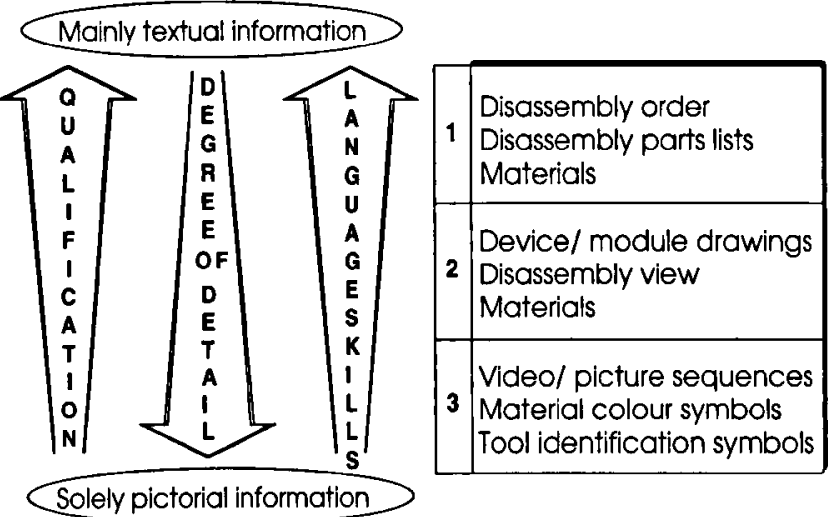

Fig. 8: Qualification-matched provision of work instructions

The degree of detail in the work instructions will rise with decreasing workperson qualifications and language skills, culminating in completely text-free information (video sequences, picture sequences, use of shape and colour symbols for assigning tools and materials). Figure 8 shows three of these qualification levels: in the topmost level, disassembly parts lists or the callable disassembly order are sufficient as information, while in the lower levels technical drawings, video sequences and/or picture sequences are utilized for presenting work-related information.

Tools, materials, components for re-use are there identified by appropriate shape and colour symbols.

Figure 9 shows two examples of workplace information - e.g. in the second level components for disassembly are marked in an exploded view drawing and assigned by a specific colour coding to old material groups.

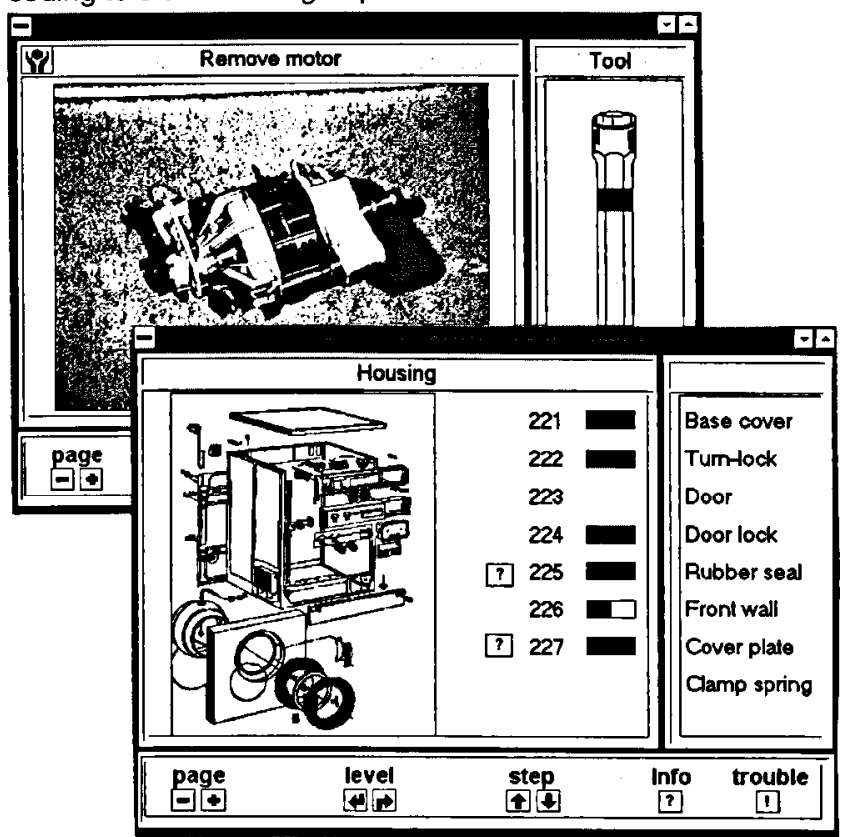

Fig. 9: Information display at the disassembly station

\section{Summary and further developments}

Further development of the software prototypes presented here aims at providing computer-aided design for recyclability and disassembly support in the future.
The objective of development work on the design subsystem is to expand the assessment methods presented here by including life-cycle-oriented cost analysis. In addition, computer-aided generation of disassembly graphs in dependence on disposal and recycling strategies is planned. Further expansion of the consultation modules will integrate expert design knowledge in the form of material compatibility matrices, for example.

In the disassembly subsystem, the initial stage of expansion will feature implementation of the disassembly planning and disassembly support modules. Future development work will target quotation creation based on existing disassembly data of similar products to precalculate causally correlated and product-specific disposal costs. Further on computerized learning processes will be used for automatic disassembly data acquisition from information available in heterogeneous formats from earlier product life-cycle phases.

The longer-term objective is to integrate the software systems developed into data processing operations (CAD, MRP, etc.).

\section{Literature}

[A193] Alting, L., Jorgensen, J., 1993, The life cycle concept as a basis for sustainable industrial production. Annals of the CIRP, Vol. 42/1.

[Br93] Breiing, A., 1993, Neue Gesichtspunkte zur Gewinnung von Bewertungskriterien. In Konstruktion 45.

[Bu68] Busacker, R., 1968, Endliche Graphen und Netzwerke. R. Oldenburg Verlag, München.

[Cz78] Czeranowsky, N., 1978, Strukturuntersuchungen von Baugruppen zur Entwicklung einer Konstruktionslogistik. Dissertation, TU Hannover.

[Ge86] Gehrmann F., 1986, Konstruktion und werterhaltendes Recycling niederwertiger Gebrauchsgüter. VDI-Fortschrittsberichte, Reihe 15, Nr. 40, Düsseldorf.

[Gr91] Grob, R., 1991, Produktverwertung durch Wiederverwendung von Teilen und Materialien. Vortrag an der Universität (TH) Karlsruhe, Karlsruhe.

[Gü91] Günther, K., 1991, Ökobilanzen als Grundlage eines Umwelt- Auditings. In Umwelt Auditing, Ulrich Steger (Hrsg.).

[Jo93] Jovane, F. a.o., 1993, A Key Issue in Product Life Cycle: Disassembly. Keynote paper in Annals of the CIRP Vol. 42/2.

[Re87] Reibnitz, U., 1987, Szenarien und Optionen für die Zukunft. McGraw-Hill Book Company GmbH, Hamburg.

[Se93] Seliger, G., Hentschel, C., 1993, Von der Montage zur Demontage - Einfälle zur Verwertung von Abfällen. Workshop Recycling, 1. Chemnitzer Konstrukteurstage.

[Sp93] Spath, D., Weule, H.,1993, Intelligent Suppont Mechanisms in Adaptable Human-Computer Interfaces. Annals of the CIRP, Vol. $42 / 1$.

[St91] Statistisches Bundesamt, 1991, Umweltschutz. In Fachserie 19, Reihe 1.2, Wiesbaden.

[VD193] Verein Deutscher Ingenieure, 1993, Konstruieren recyclinggerechter technischer Produkte. VDIRichtlinie 2243.

[We89] Weule, H., Friedmann, Th., 1989, Computer-aided Product Analysis in Assembly-Planning. Annals of the CIRP, Vol. 38/1.

[We93] Weule, H., 1993, Life-cycle-analysis: a strategic element for future products and manufacturing technologies. Annals of the CIRP, Vol. 42/1.

[Zü91] Züst, R., 1991, Produkt- und Produktionsgestaltung: Wie weiter? In Management Zeitschrift, Zürich. 